\title{
Back to the future: Stoic wisdom and psychotherapy for neuropsychiatric conditions
}

\author{
Andrea E Cavanna*,1,2,3 \\ ${ }^{1}$ Department of Neuropsychiatry, BSMHFT \& University of Birmingham, Birmingham, UK \\ ${ }^{2}$ School of Life \& Health Sciences, Aston Brain Centre, Aston University, Birmingham, UK \\ ${ }^{3}$ Sobell Department of Motor Neuroscience \& Movement Disorders, Institute of Neurology \& University College London, London, \\ UK \\ *Author for correspondence: Tel.: +44 121 3012317; Fax: +44 121 3012291; a.e.cavanna@bham.ac.uk
}

First draft submitted: 18 December 2018; Accepted for publication: 19 December 2018; Published online: 15 January 2019

Keywords: cognitive-behavioral therapy $\bullet$ neurology $\bullet$ neuropsychiatry $\bullet$ psychotherapy $\bullet$ quality of life $\bullet$ Stoicism

It has long been acknowledged that most neurological disorders are chronic in nature and available treatment interventions are rarely curative. A relatively more recent acquisition is the clinical observation that most neurological disorders resulting from central nervous system pathologies are associated with significant psychiatric and behavioral disturbances and should be considered neuropsychiatric conditions tout court [1]. This is true, for example, for basal ganglia disorders, whether they are currently classed as neurodevelopmental or neurodegenerative movement disorders. Both Tourette syndrome (hyperkinetic movement disorder with neurodevelopmental etiopathogenesis) and Parkinson disease (hypokinetic movement disorder with neurodegenerative etiopathogenesis) clinically present with a combination of motor and nonmotor features sharing a chronic course [1]. Specifically, Tourette syndrome, with its combination of tics and obsessive-compulsive symptoms and/or attention-deficit and hyperactivity symptoms, has recently been referred to as 'paradigmatic neuropsychiatric disorder' [2]. Parkinson disease, with its association with rigid-hypokinetic (or tremor) features and anxiety/affective symptoms (or iatrogenic impulse dysregulation and psychosis), has been regarded as 'the quintessential neuropsychiatric disorder' [3]. The most effective treatment interventions currently available consist in pharmacotherapy targeting dopaminergic pathways. Antidopaminergic agents can decrease tic frequency and severity in patients with Tourette syndrome, whereas dopamine replacement therapy can improve rigidity, bradykinesia, and, to a lesser extent, tremor, in patients with Parkinson disease. Unfortunately, neither pharmacological interventions nor more invasive approaches such as deep brain stimulation surgery are known to be curative per se. Moreover, it is well recognized that both antidopaminergic and dopaminergic agents can result in psychiatric/behavioral adverse effects (e.g. on vigilance/affect and impulsivity/reward-seeking behaviors, respectively) [1]. It is therefore hardly surprising that the focus of clinical practice and research has progressively shifted from objective neurological outcome measures to patient-reported health-related quality of life. To stick to the example of movement disorders, it has consistently been shown that nonmotor manifestations such as affective symptoms can bear a more significant impact on health-related quality of life than motor impairment $[4,5]$. Psychological therapies, especially cognitive-behavioral approaches, have been shown to be highly effective first-line treatment interventions for patients with affective and anxiety disorders, i.e. the main determinants of health-related quality of life across neuropsychiatric conditions. Based on the available evidence, in the UK, the National Institute for Health and Clinical Excellence has made recommendations for the use of cognitive-behavioral therapy in the treatment pathways of adult patients with depression in the context of a chronic physical health problem [6], with relevant implications to a wide range of neuropsychiatric conditions.

It has been suggested that there have been three successive 'waves' in terms of modern psychotherapy interventions throughout the second half of the XX century and the beginning of the XXI century [7]. The first wave (behavior therapy) originated from Burrhus F Skinner's popular doctrine of behaviorism, at least in part as a reaction to Freudian models of the mind and psychodynamic therapy. The transition between the first and the second

Future Medicine 
wave marked the birth of cognitive-behavioral therapy approaches: this passage has often been described as the clinical equivalent of the cognitive revolution that took place in the field of scientific psychology thanks to the work of Noam Chomsky and other pioneers of cognitive sciences. The revolution of the 'second wave' of psychotherapy consisted in expanding the previous model of environmental triggers and behavioral responses by interposing a cognitive mediator that had been absent in the 'first wave' of behavioral approaches [8]. Albert Ellis' rational emotive behavior therapy and Aaron Beck's cognitive therapy championed the 'second wave' by developing popular clinical counterparts to the cognitive revolution in the late 1950s and 1960s. It was Albert Ellis who first acknowledged ancient philosophers as the source of the therapeutic value of rationality as cognitive mediator between environmental challenges and emotional reactions. Interestingly, it has been noted that both Ellis' and Beck's early writings gave credit to the Stoics as the ancient progenitors of modern cognitive-behavioral therapy, as their approach was anticipated by the fundamental Stoic belief that emotions arise from an interaction between human reason and the environment [9]. Stoicism is a Hellenistic school of philosophy founded by Zeno of Citium at the beginning of the III century BC inspired by Socrates' teaching. Most of the surviving Stoic texts were written by or about the Roman Stoics (Seneca, Epictetus, Marcus Aurelius), that is, toward the end of the 600-year period during which the classical phase of this philosophical tradition flourished. Although the fact that clinical psychology grew out of the discipline of ancient philosophy is often overlooked by modern psychotherapists, recent studies have convincingly shown that modern cognitive therapy owes much to the writings and ideas of the Stoics of Rome $[9,10]$. Specifically, the philosophy of Epictetus is cited by both Ellis and Beck as a forerunner of modern cognitive therapy [11]. Epictetus' most quoted passage from the 'Enchiridion' ('Handbook') clearly illustrates the close link between Stoicism and cognitive-behavioral therapy: "Men are disturbed not by things but by the views which they take of them [... ] when, therefore, we are hindered, or disturbed, or grieved, let us never blame anyone but ourselves: that is, our own judgments." The cognitive-behavioral therapist also assumes that the individual's primary problem has to do with his construction of reality, rather than with reality itself. Ellis himself referred to Epictetus as "a remarkably wise Stoic [who] pointed out some of two thousand years ago that you choose to overreact to the obnoxious behavior of others while you could more wisely choose to react in a very different manner" [12].

The Stoic and cognitive theories about the operation of reason upon emotion and behavior have striking parallelisms. Several analogies draw on the meaning of the ancient Greek term 'arete', which is often mistranslated as 'virtue', whereas it simply referred to 'excellence' (devoid of moral value). In this sense, 'arete' could be attributed to nonliving things: for example, the 'arete' of a knife would be its sharpness. Likewise, the 'arete' of human beings is rationality, that is, excellence in the feature (reason) which characterizes human nature. According to the Stoic doctrine, emotional reactions, far from being irrational and impossible to analyze, are judgments based on reason - and therefore amenable to control and manipulation. In fact, Epictetus himself compared the role of the philosopher to that of a physician, consistently with the tradition of ancient philosophy as medicine of the soul or 'psychotherapy' [13]. The Stoic philosopher as psychotherapist used to help others to achieve 'reasoned emotions'. Cultivating 'arete' through daily practice was seen as the way to achieve the good life ('eudaimonia'), free of irrational anxieties and sorrows. In a similar fashion, modern cognitive-behavioral therapists place emphasis upon the rational approach to alter dysfunctional emotions and therefore treat anxiety and affective disorders.

The 'third wave' of psychotherapy was heralded in a 2004 article by Steven Hayes as a group of therapies encompassing mindfulness-based cognitive therapy and acceptance and commitment therapy, among others [7]. In 2011, the same author and his colleagues proposed 'contextual cognitive behavioral therapy' as a new designation for the 'third wave' group of psychotherapy [14,15]. It is worth noting that the practice of mindfulness is not new to the western tradition, as it can be traced back to the primarily Stoic exercise of attention ('prosoche', or 'concentration on the present moment'). Thanks to this attitude, the philosopher is fully aware of what he does at each instant, and he wills his actions fully, thereby freeing himself from unhealthy emotions, which are rooted in the past (depression) or in the future (anxiety). The late French scholar Pierre Hadot argued that for the Stoics the exercise of attention to the present moment is, in a sense, the key to a wider range of spiritual exercises [16]. As part of their cognitive-behavioral treatment intervention, patients may be asked to keep a diary (journal) or write down their thoughts and behavior patterns. Again, the practice of recording own thoughts and feelings can be traced back to Marcus Aurelius' 'Meditations', a book that was not intended for publication and is sometimes titled 'To himself, reflecting its original purpose - an exercise of reflective practice of Stoic discipline [17]. Modern versions of the Stoic spiritual exercises have recently been presented in 'The Daily Stoic Journal [18] (that builds on Ryan Holiday's 2016 book 'The Daily Stoic' [19]) and are due to feature in the forthcoming 'Live like a Stoic' [20] 
by Massimo Pigliucci, author of the 2017 best seller 'How to be a Stoic', an imaginary dialogue with Epictetus [21]. Finally, an original study by Donald Robertson weaving the life and philosophy of Marcus Aurelius with insights from modern psychology is due to appear in 2019 [22]: at the dawn of the new millennium Stoicism seems to be alive and at the heart of modern psychotherapy. Back to the future?

\section{Financial \& competing interests disclosure}

The author has no relevant affiliations or financial involvement with any organization or entity with a financial interest in or financial conflict with the subject matter or materials discussed in the manuscript. This includes employment, consultancies, honoraria, stock ownership or options, expert testimony, grants or patents received or pending, or royalties.

No writing assistance was utilized in the production of this manuscript.

\section{Open access}

This work is licensed under the Attribution-NonCommercial-NoDerivatives 4.0 Unported License. To view a copy of this license, visit http://creativecommons.org/licenses/by-nc-nd/4.0/

\section{References}

1. Cavanna AE. Motion and Emotion. Springer, NY, USA (2018).

2. Cavanna AE. Gilles de la Tourette syndrome as a paradigmatic neuropsychiatric disorder. CNS Spectr. 23(3), 213-218 (2018).

3. Weintraub D, Burn DJ. Parkinson's disease: the quintessential neuropsychiatric disorder. Mov. Disord. 26(6), 1022-1031 (2011).

4. Evans J, Seri S, Cavanna AE. The effects of Gilles de la Tourette syndrome and other chronic tic disorders on quality of life across the lifespan: a systematic review. Eur. Child. Adolesc. Psychiatry 25(9), 939-948 (2016).

5. Balestrino R, Martinez-Martin P. Neuropsychiatric symptoms, behavioural disorders, and quality of life in Parkinson's disease. J. Neurol. Sci. 373, 173-178 (2017).

6. National Institute for Health and Clinical Excellence. Depression in adults with a chronic physical health problem: treatment and management (Clinical Guideline 91) (2009). www.nice.org.uk/CG91

7. Hayes SC. Acceptance and commitment therapy, relational frame theory, and the third wave of behavior therapy. Behav. Ther. 35, 639-665 (2004).

8. Ruggiero GM, Spada MM, Caselli G, Sassaroli S. A historical and theoretical review of cognitive behavioral therapies: from structural self-knowledge to functional processes. J. Ration. Emot. Cogn. Behav. Ther. 36, 378-403 (2018).

9. Robertson D. The philosophy of cognitive-behavioural therapy (CBT): Stoic philosophy as rational and cognitive psychotherapy. Karnac, London, UK (2010).

10. Robertson D. The Stoic influence on modern psychotherapy. In: The Routledge Handbook of the Stoic Tradition. Sellars J (Ed.). Routledge, London, UK, 374-388 (2016).

11. Still A, Dryden W. The Historical and Philosophical Context of Rational Psychotherapy: the Legacy of Epictetus. Karnac, London, UK (2012).

12. Montgomery RW. The ancient origins of cognitive therapy: the reemergence of Stoicism. J. Cogn. Psychother. 7(1), 5-19 (1993).

13. Xenakis I. Epictetus: Philosopher-Therapist. Martinus Jijhoff, The Hague, The Netherlands (1969).

14. Hayes SC, Villatte M, Levin ME, Hildebrandt M. Open, aware, and active: contextual approaches as an emerging trend in the behavioral and cognitive therapies. Annu. Rev. Clin. Psychol. 7, 141-168 (2011).

15. Dimidjian S, Arch JJ, Schneider RL, Desormeau P, Felder JN, Segal ZV. Considering meta-analysis, meaning, and metaphor: a systematic review and critical examination of 'third wave' cognitive and behavioral therapies. Behav. Ther. 47(6), 886-905 (2016).

16. Hadot P. Philosophy as a Way of Life: Spiritual Exercises from Socrates to Foucault. Oxford: Blackwell, Oxford, UK (1995).

17. Hadot P. The Inner Citadel: the Meditations of Marcus Aurelius. Harvard University Press, MA, USA (1998).

18. Holiday R, Hanselman S. The Daily Stoic Journal: 366 Days of Writing and Reflection on the Art of Living. Portfolio, NY, USA (2017).

19. Holiday R. The Daily Stoic: 366 Meditations on Wisdom, Perseverance, and the Art of Living. Portfolio, NY, USA (2016).

20. Pigliucci M, Lopez G. Live Like a Stoic. Rider, London, UK (2019).

21. Pigliucci M. How to be a Stoic. Rider, London, UK (2017).

22. Robertson D. How to Think Like a Roman Emperor: the Stoic Philosophy of Marcus Aurelius. St Martin's Press, NY, USA (2019). 
